\title{
Analysis on Relay Protection of User Lateral Grid-connected PV Power Generation
}

\author{
Du Peidong ${ }^{1}$, Zhang Jianhua ${ }^{1}$, Peng Jing ${ }^{1}$, Yue Lin $^{1}$, Wu Yingting ${ }^{2}$ \\ ${ }^{1}$ State Grid Gansu Electric Power Research Institute, Lanzhou, 730050, China \\ ${ }^{2}$ State Grid LongNan Electric Power Supply Company, LongNan, 742500, China \\ peidong9@163.com
}

Keywords: user lateral, PV power, grid-connected, distribution network, relay protection

\begin{abstract}
The paper analyzes the influence of user lateral grid-connected PV generation on relay protection of distribution network, and proposes the opinions for the economic technique and selectivity of protection. The paper applies DIgSILENT PowerFactory software to make simulation calculation and analysis on the actual projects, and proposes relay protection allocation scheme and protection setting rules, which provides engineering references for the grid-connected PV power projects.
\end{abstract}

\section{Introduction}

In recent years, it has become the important development strategy for many countries to develop and use clean energy [1]. As a reproducible and non-pollution generation method of using photovoltaic effect to directly transform solar energy into electricity energy, photovoltaic power generation develops rapidly in the world. Especially the grid-connected PV power system achieves rapid development, the reason for which is that it has no batteries, which reduces the cost and maintenance of power station. The statistical data indicates that global grid-connected PV power generation accounts for $80 \%$ of PV power generation market share, and becomes the dominant market of PV power generation [2].

In China, since 2008, grid-connected PV power generation has developed rapidly. Lots of megawatt-level PV power stations invests grid connection, and PV power generation technique becomes the research hot. For the problems to be researched by grid-connected PV power generation technique, the influence of grid-connected PV power generation on relay protection of distribution network is a key factor of restricting PV system to connect with distribution network. In the real grid-connected PV projects, especially lots of Golden Sun Projects use user lateral grid connection, and how to allocate relay protection needs to be researched.

The paper analyzes the influence of grid connection of user lateral grid-connected PV power system on distribution network, and proposes the relay protection setting scheme of user lateral grid-connected PV power system combined with the actual projects.

\section{Characteristics of User Lateral Grid-connected PV Power System}

PV power system is incorporated into power grid at accounting point user lateral, which is called user lateral grid connection [3]. User lateral grid-connected PV poser station uses the rule of on-site and distributed access. For small PV power stations, when single-point access capacity is less than $200 \mathrm{kw}, 400 \mathrm{~V}$ distribution network is generally accessed. The access capacity is small, and the access voltage grade is low, which has little influence on distribution network. And the relay protection problem is not considered singly. For small and medium-sized power stations, the single-point access capacity is generally greater than $1 \mathrm{MW}$, and it accesses the distribution network when it increases to $10 \mathrm{kV}$ or $35 \mathrm{kV}$ by the transformer. The access capacity is great, and the access voltage grade is high and it has great influence on distributed network, so the paper focuses on analyzing relay protection under the conditions. 
(1) PV batteries of PV power stations are generally distributed on the top of workshops and large offices. And multi-access point grid connected way is generally used to supply the power for the nearest electric equipment [4].

(2) The integration points are close to the end of the load of distribution network, and the load power change is great. The PV penetration of large and medium-sized PV power stations is generally high ( it is greater than $20 \%$ ).

(3) It is general that the distribution network has been established for many years, and the matched relay protection value has been determined and operated before PV power supply accesses. The relay protection of distribution network of PV power supply is weak, which has the characteristics of simple protection, single type, many feeder series, complicated time coordination and bad protection speed and selectivity [5].

\section{Influence of User Lateral Grid-connected PV Power System on Relay Protection of Distribution Network}

After PV power accesses distribution network on user side, the distribution network changes from single power system to multi-power system. The difference from traditional synchronous generator and asynchronous generator is that PV power power is inverter power, and the control way is constant power removal. Therefore, when grid-connected PV inverter is short out, the fault current is generally less than 1.5 times of the rated current.

\section{Practical Engineering Example Analysis}

The paper takes a user lateral grid-connected power project as an example, and analyzes the relay protection after PV power accesses.

In the project, PV power supply accesses the user distribution network through two grid connection points, and connects with the system by user transformer substation. The user transformer substation installs 2 main transformers (size:SFZ10-12500/35) which operate in parallel. The rated power of each PV inverter is 500kVA, and they are divided into two groups ( the installed capacity of PV1 is 3MWp, and that of PV2 is 3.5MWp). And it increases to $10 \mathrm{kV}$ through the transformer (size: YJLV22-10-(3×240)) . The power of the internal Load 1 of the user is $6430 \mathrm{~kW}$, the idle is $2486 \mathrm{kvar}$. And the active load of Load 2 is $6535 \mathrm{~kW}$, and the idle is 2504.kvar.

The original relay protection setting includes system variable $35 \mathrm{kV}$ outlet allocates three sections of current protection and reclosure. The main transformer configures differential protection and compound voltage blanking protection. The user $10 \mathrm{kV}$ outlet allocates two sections of current protection.

System parameters: $\mathrm{SB}=100 \mathrm{MVA}, \mathrm{XS}=0.135$ under maximum operation mode, and $\mathrm{XS}=0.2$ under minimum operation mode. The electrical resistivity of aluminum conductor is 31.5 (ohm $\mathrm{mm} 2) / \mathrm{km}$, the main user transformer variance is Uk=8\%, and the boost is $\mathrm{Uk}=4.5 \%$ and PV short-circuit current is 1.2 times of the rated current (the measured value). The short-circuit current of grid-connected PV system is shown in Table 1 and Table 2. All current values return to $10 \mathrm{kV}$ lateral numerical value. 
Tab.1 Short-circuit current under maximum operation mode

\begin{tabular}{|l|l|l|l|l|l|}
\hline \multirow{3}{*}{$\begin{array}{l}\text { Short-circuit point } \\
\text { number }\end{array}$} & $\begin{array}{l}\text { Average } \\
\text { operating } \\
\text { value }\end{array}$ & $\begin{array}{l}\text { Steady } \\
\text { short } \\
\text { circuit } \\
\text { current } \\
\text { RMS }\end{array}$ & $\begin{array}{l}\text { Short } \\
\text { circuit } \\
\text { current } \\
\text { impact } \\
\text { value }\end{array}$ & $\begin{array}{l}\text { Maximum } \\
\text { RMS of } \\
\text { short-circuit } \\
\text { current }\end{array}$ & $\begin{array}{l}\text { Short } \\
\text { circuit } \\
\text { capacity }\end{array}$ \\
\cline { 2 - 6 } & $\begin{array}{l}\text { U } \\
(\mathrm{kV})\end{array}$ & $\begin{array}{l}\text { I } \\
(\mathrm{kA})\end{array}$ & $\begin{array}{l}\text { ich } \\
(\mathrm{kA})\end{array}$ & $\begin{array}{l}\text { Ich } \\
(\mathrm{kA})\end{array}$ & $\begin{array}{l}\text { S } \\
\text { (MVA) }\end{array}$ \\
\hline D1 & 10.5 & 6.138 & 11.284 & 6.667 & 11.720 \\
\hline D2 & 10.5 & 5.869 & 10.790 & 6.375 & 11.207 \\
\hline E1 & 10.5 & 6.138 & 11.284 & 6.667 & 11.720 \\
\hline E2 & 10.5 & 6.068 & 11.156 & 6.591 & 11.587 \\
\hline G & 0.27 & 0.552 & 1.016 & 0.600 & 1.055 \\
\hline H1 & 0.27 & 0.791 & 1.454 & 0.859 & 1.510 \\
\hline K & 0.27 & 0.554 & 1.019 & 0.602 & 1.058 \\
\hline L1 & 0.27 & 0.794 & 1.460 & 0.863 & 1.517 \\
\hline
\end{tabular}

Tab.2 SCC under minimum operation mode

\begin{tabular}{|c|c|c|c|c|c|}
\hline \multirow{2}{*}{$\begin{array}{l}\text { Short-circuit } \\
\text { point } \\
\text { number }\end{array}$} & $\begin{array}{l}\text { Average } \\
\text { operating } \\
\text { value }\end{array}$ & $\begin{array}{l}\text { Steady short } \\
\text { circuit } \\
\text { current RMS }\end{array}$ & $\begin{array}{l}\text { Short circuit } \\
\text { current } \\
\text { impact value }\end{array}$ & $\begin{array}{l}\text { Maximum } \\
\text { RMS of } \\
\text { short-circuit } \\
\text { current }\end{array}$ & $\begin{array}{l}\text { Short circuit } \\
\text { capacity }\end{array}$ \\
\hline & $\begin{array}{c}\mathrm{U} \\
(\mathrm{kV})\end{array}$ & $\begin{array}{c}\mathrm{I} \\
(\mathrm{kA})\end{array}$ & $\begin{array}{c}\text { ich } \\
(\mathrm{kA})\end{array}$ & $\begin{array}{c}\text { Ich } \\
(\mathrm{kA})\end{array}$ & $\begin{array}{c}\mathrm{S} \\
(\mathrm{MVA})\end{array}$ \\
\hline D1 & 10.5 & 5.629 & 10.348 & 6.114 & 10.749 \\
\hline D2 & 10.5 & 5.401 & 9.931 & 5.868 & 10.315 \\
\hline E1 & 10.5 & 5.629 & 10.348 & 6.114 & 10.749 \\
\hline E2 & 10.5 & 5.570 & 10.241 & 6.051 & 10.637 \\
\hline $\mathrm{G}$ & 0.27 & 0.548 & 1.008 & 0.595 & 1.047 \\
\hline $\mathrm{H} 1$ & 0.27 & 0.782 & 1.438 & 0.849 & 1.493 \\
\hline $\mathrm{K}$ & 0.27 & 0.550 & 1.011 & 0.597 & 1.050 \\
\hline L1 & 0.27 & 0.785 & 1.444 & 0.853 & 1.500 \\
\hline
\end{tabular}

From the table, we can see that the short-circuit current of $10 \mathrm{kV}$ side achieves thousands of Ann, most of which is provided by system side power supply. The short circuit capacity of PV power supply is little, and the provided short circuit current is little. The influence on current protection can be ignored. Based on the above calculation analysis, the paper makes the following protection setting scheme for the system in Figure 2.

(1) $35 \mathrm{kV}$ inlet system side is installed PT, and the reclosing way is changed into synchronous check.

(2) The user relay protection setting has no change, and only the current value of $10 \mathrm{kV}$ workshop is reset.

(3) For two tie lines, the circuit is short ( $400 \mathrm{~m}$ and $100 \mathrm{~m}$ ). In order to make coordination easy, the optical-fiber current differential protection is allocated as the main protection.

(4) 8 lines of PV bus are string type, and two sections of current protection is allocated.

(5) A set of small current fault line selection setting is configured on PV bus.

(6) The project is medium-sized PV power station. A set of safe automatic control setting is installed according to PV Power Station Access Power Network Technique Specifications of State Grid Corporation of China. 
For the above relay protection setting schemes, the paper makes the following setting principles.

(1) For PV line-transforming protection, a section of over-current is set by the maximum short circuit current of evading the low-voltage lateral failure side, and the time limit is OS. The over-current value is set by the maximum load current of evading the transformer, and the time limit is $0.5 \mathrm{~s}$.

(2) Tie line protection. The differential motion current value is set by evading the maximum imbalanced current.

(3) The over-current constant of outlet 1 and outlet 2 of $10 \mathrm{kV}$ workshop is set by the minimum short circuit current (the circuit is short, and is only $800 \mathrm{~m}$ ), and the time limit is $0.5 \mathrm{~S}$. The over-current value of the second section is set by the maximum load current of evading the line, and the time limit is $1 S$.

The project was operated smoothly in November 2011, and grid-connected power completes.

\section{Conclusions}

Compared with other PV grid-connected ways, user lateral grid-connected PV power has little influence on relay protection of distribution network, and requires little change for the original protection configuration of the distribution network. While ensuring the stability of distribution network, the relay protection of PV power supply should be simplified from the economic perspective, which has realistic significance for the promotion and application of grid-connected PV power technique. The protection of PV power supply requires to be enhanced, and the fixed value setting should be more flexible and practical, which can reduce the change of the original protection of distribution network and ensures the stability of the system. At present, lots of Golden Sun Projects are being established, and some projects have been operated. The analysis on relay protection of user lateral grid-connected PV power should be after the completion of the project. And the analysis, verification and improvement is made in the subsequent operation of PV power station.

\section{References}

[1] Liu Jizhen, Development strategy of establishing large power subject system to serve low carbon energy [J], China Higher Education, 2010,2:18-20.

[2] Yin Lu, Zhao Zhengming, Status and development of PV grid-connected technique and market [J], World of Inverters, 2008, 10:34-40.

[3] Dong Yajun, Realizing PV power user lateral grid connection needs to adjust policies and innovation mechanism [EB/OL], [2011-09-07],http://www.chinadaily.com.cn/hqgj/jryw/ 2011-09-07/content_3722411.html.

[4] Zhang Limei, Tang Wei, Zhao Yunjun, Wang Shaolin, Comprehensive evaluation of influence of distributive power on distribution network [J], Power System Protection and Control, 2010,38(21):132-135. 